merary cuspids in the anterior and two in the posterior part of the left arch; the molars have been extracted. Supernumerary teeth are not confined to these localities but may be observed at any point in the dental arch (Figs. 24 and 25). The primitive cone-shaped tooth is rarely observed in the lower jaw. In twenty-six years practice I have not seen a case. The mobility of the lower jaw prevents that mal-adjustment to environment present in the upper.

The continual shortening in both directions of the jaw causes the third molars frequently so to wedge in between the angle of the jaw and the second molar that eruption, if possible, is difficult. The third molar is often absent in the Caucasion races. In 46 per cent. of 670 patients it was missing. Frequently its development is abortive. This tooth in the struggle for existence seems destined to disappear. It is more often absent from the upper than the lower jaw. When absent or badly developed the jaw is smaller and frequently teeth irregularities, nasal stenosis, nasal

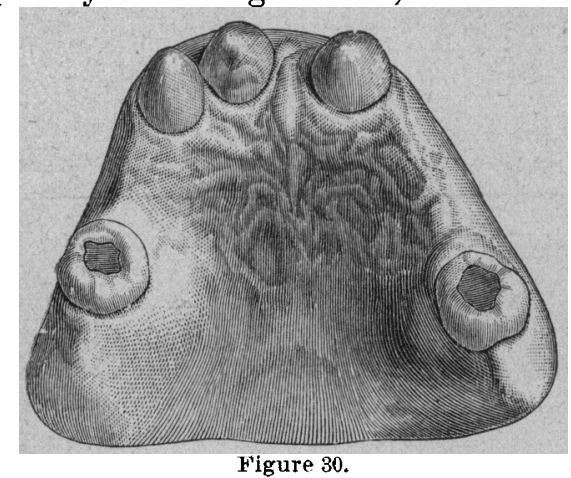

bone and mucous membrane hypertrophy, adenoids and eye disorders coëxist. Figure 26 shows absence of the left third molar with irregularities of that side of the arch. In Figure 27 both third molars are seen to be missing coincident with irregularities on both sides of the arch. Anteriorly the lateral incisors are most often wanting; 14 per cent. of the laterals were wanting in 670 patients. In the progress of evolution man has lost one lateral upon each side of the mouth and the second lateral seems also destined to disappear. In Figure 28 the left lateral incisor has disappeared and in Figure 29 both lateral incisors are absent. Not infrequently does it occur that centrals, cuspids, bicuspids and even molars are absent, even their germs are not detectable. Figure 30 illustrates a cast showing three supernumeraries in the anterior part of the mouth and but two molars. The absence of teeth indicates lack of development of germs due either to heredity or defective maternal nutrition of the line of conception or during early pregnancy.

( To be continued.)

\section{ERB'S PRIMARY MUSCULAR ATROPHY.}

Read in the Section on Neurology and Medical Jurisprudence, at the Forty-seventh Annual Meeting of the American Medical Association at Atlanta, Georgia, May 5-8, 1896. BY ELMORE S. PETTYJOHN, M.D.

MEDICAL SUPERINTENDENT ALMA SANITARIUM, ALMA, MICH.

Since Duchenne first described progressive muscular atrophy in adults and infants and regraded each form as of peripheral origin, the study of the clinical history and pathology of muscular dystrophies has only partially decided which are of muscular and which of spinal origin. We now believe that the hereditary form found during infancy and early life, especially if it attacks several members of the same family, is of muscular origin, and certainly so if there are present postmortem hypertrophied muscular fibers side by side with atrophied and degenerated fibers, and with no changes in the anterior horns of gray matter of the cord nor in the nuclei of the fourth ventricle or aqueductus sylvii.

One chief reason for considering this much talked about disease is the desire to establish a definite symptomatology, to accomplish a differential diagnosis and arrive at the rational treatment for the benefit of the patient, rather than to originate classifications.

Idiopathic muscular atrophy is primarily disease of childhood and youth and usually develops before the age of 20 . It is more frequent in males than

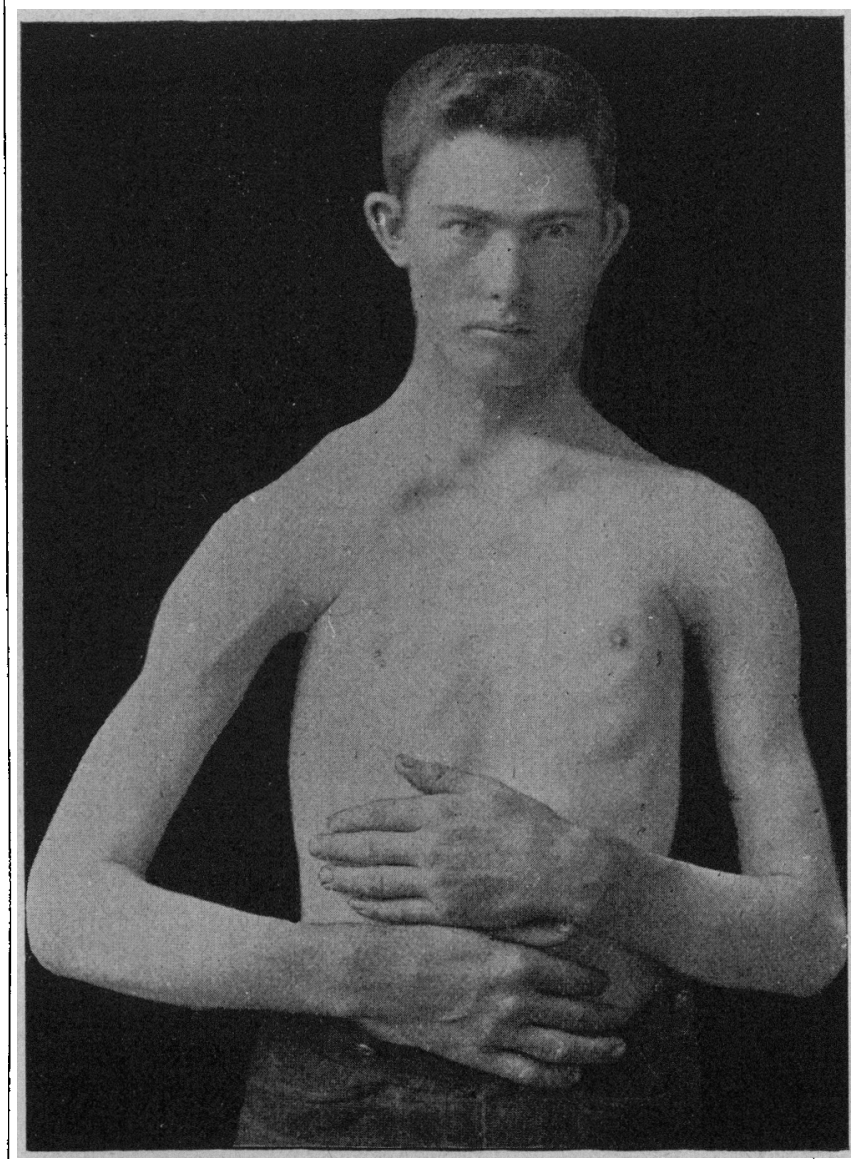

Fig. 1.-Primary museular atrophy. Age 22. Left side shows more atrophy than right. Hands large by comparison. Right shoulder droops. Pectoral muscles wasted. Forearms unafiected. Dr. E. S. Pettyjohn.
Case 1 . Case 1

females, probably due to transmission through the mother, though she herself is exempt, as the son usually inherits the peculiarities of the mother and the daughter those of the father. In this way it is hereditary in three-fourths of the cases, and often appears in several members of the same family, but usually of the same type in the different members of the same family.

The onset of the disease is gradual and the atrophy and weakness progress simultaneously with or without any initial hypertrophy. In the parts affected the disease slowly increases and thence spreads. The shoulder girdle is first affected, i.e., the pectorals, the trapezii, rhomboidii, latissimus dorsi, the upper arm muscles and the supinators, and later 
the forearms, glutei, thighs and legs. The patient is or lost, never increased. The sphincters are not often unaware of the wasting of these muscles on affected. The disease is painless. account of their relative unimportance. The deltoids are rarely involved and the serratus magnus often escapes noticeable changes.

On electrical examination the irritability of the affected muscles is usually lessened, on the use of either current and either pole, out of proportion to the atrophy present. The typical reaction of degeneration is not present; however, the action is not entirely normal. Were we to divide the reaction of degeneration into three stages they might be designated: Simple atrophy, atrophy with muscular cell proliferation and atrophy with muscular cirrhosis. The

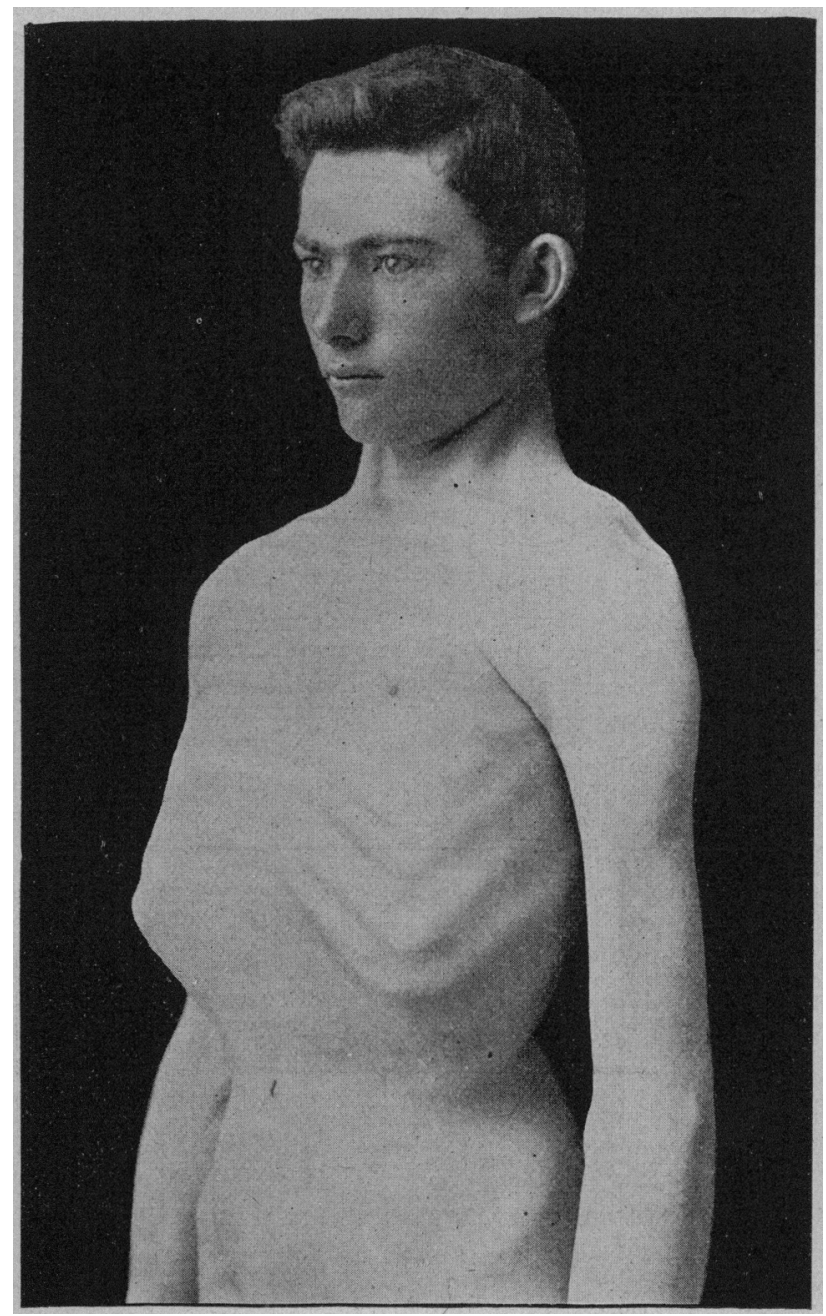

FIG. 2,-Chest expansion, nipple line 37 inches: tip of sternum $401 / 2$ inches. Intercostals unaffected. Bieeps atrophied with deltoid and pectorales. (Conditions not well shown in the picture.) The scapula opposition. Dr. E. S. Pettyjohn. Case 1.

reaction found in this disease would be that of the first mentioned stage. Febrillary twitchings are absent, though not invariably, and the sensibility to the faradic current and heat and cold is usually unimpaired.

The absence of nerve irritation alone would seem to prove the atrophy to have begun in the end organs of the nerve, and also in the nerve itself. Implication of the nerve is shown by the increased action of the muscles when the electrode is placed over the motor point, as compared with the reaction obtained when placed over the muscles. The reflexes are weakened The
Aside from heredity, acute febrile diseases, especially scarlatina and diphtheria, and over-exertion, lack of good food and exposure to vicissitudes of the weather undoubtedly enter into the etiology. The course and duration (from ten to thirty years) of the disease are exceedingly variable, but can undoubtedly be influenced by treatment. Death usually occurs from some intercurrent disease.

The treatment in its prophylactic form should include the prohibition of marriage of one so afflicted,

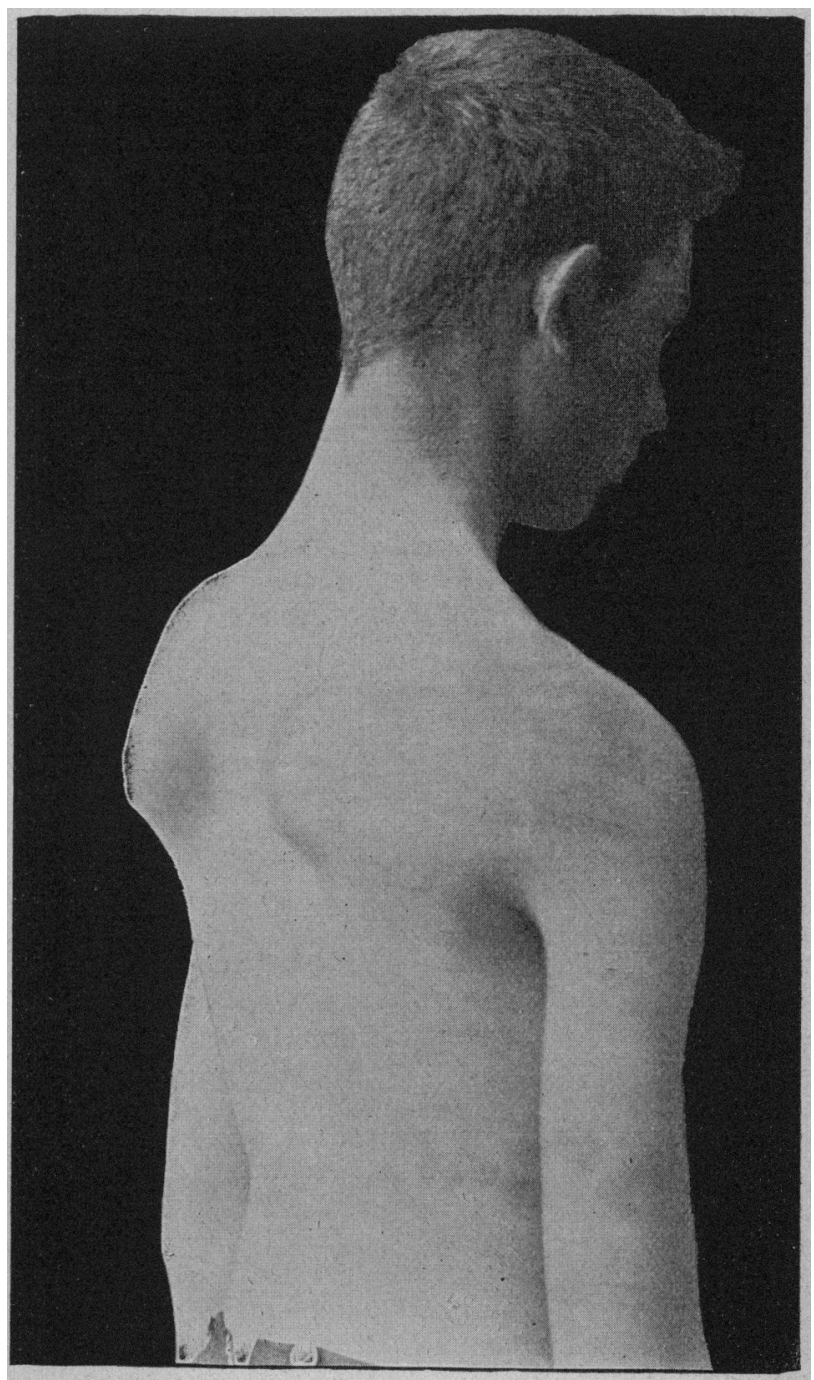

FIc. 3.-Wing-like projection of scapula, showing atrophy of trapezii and serrati. Drooping of right shoulder. Triceus complicated as well as the entice shoulder girdle. Age 22 years. Began at 14 years. Dr. E. S. Pettyjohn. Case 3.

and of bringing into the world other children by parents the physical combination of whom produced such dystrophies. Infants of such mothere should be reared by a wet nurse or by artificial feeding. All children of families where disease exists in one mem. ber, should be reared hygienically with every effort to increase and develop the muscles of the body symmetrically.

The active treatment should combine every useful agency to prevent nutritional deterioration of the skin, the muscles and the nerves supplying them. 
from has been shown to increase the assimilation and nutrition of the underlying muscles. Fomentations, followed by cold sprays, stimulate to greater activity the circulation of the part. Light friction continued for a considerable length of time and frequently repeated, especially with camphor liniment increases the cutaneous nutrition.

For the muscles, methodical, graduated exercise with or without apparatus (never tiring the muscle) will increase their nutrition. In addition to this, massage, skillfully used by the hand of an operator who understands the anatomy of the part and can select the various groups affected for treatment, is a most excellent aid to increasing the nutrition of the muscle. The wasted and degenerate tissue of the muscle is forced into the circulation, the blood vessels and lymphatics are emptied of the already accumulated débris and new material is brought to increase every elemental part. This treatment should be given twice daily, gradually increasing the force and time occupied. Electrization of the affected muscles and those in the immediate region, especially with the sinusoidal current, should be practiced daily. This should be done in an especial manner to every affected muscle. The current ought never to be strong nor continued until the sensibility is greatly increased. The current in use should rather be diminished than increased. One or two minutes should be allowed to each muscle, when the current should be distributed over several muscles; the entire séance lasting only from fifteen to twerity minutes, depending upon the area of the muscles affected.

The static current and alternating hot fomentations and ice to the spine, to stimulate the nerve centers supplying the affected groups of muscles, augments the innervation and increases the nutrition.

The very best internal remedy is, in my opinion, wholesome, nourishing food, a generous mixed diet combined with long hours of rest in bed and prolonged undisturbed sleep. Strychnia preparations combined with quinin are the best tonics. As the hemoglobin and the number of blood corpuscles are neither diminished, iron is not especially indicated.

I report a case in point: Two years ago Daniel $L$. presented himself at the sanitarium and gave the following history: Age 19, son of a farmer: one of seven children all in good health at the time. No neurotic heredity; father died at the age of 45 , of some stomach disease; mother living, in good health. Family history good. At 9 years of age had scarlatina and made an uneventful and complete recovery.

At the age of 15 he performed a hard day's work. carrying bags and pitching bundles. No immediate effects were noticed, but a month afterward he began to notice weakness in the muscles of the chest, shoulders and arms. Some time after this these muscles began to atrophy. For the six months previous to my first observation the case had grown rapidly worse. During this time he complained of being very weak and tired after very moderate effort. While swimming his companions noticed the wing-like projection of the scapulæ. He gradually grew weaker, so he was hardly able to do milking. The family called him lazy, much to his discomfort.

On examination the entire shoulder girdle was found affected. The upper intercostals and pectorals were so weakened that the breathing was largely diaphragmatic. The expansion at the nipple line thirty-seven inches, just below the sternum forty and one-half inches. When the arms were at the side the scapula projected so that the two hands could be laid between them and not be seen on the line across. The trapezii, rhomboidii, latissimus dorsi, biceps and triceps were all affected, the left sille more atrophied than the right. The forearms and hands were not noticeably changed or weakened, although the hands seemed large by contrast. $\mathrm{He}$ could not put either hand on the top of the head without the momentum of a swinging action for several seconds. On trying to lift him from the floor by placing the hands in the arm-pits the shoulders were raised nearly to the ears. He walked similarly to one with a lame back. The patellar reflexes were entirely absent, but there was no incoördination when standing. There were no muscular vibrations, convulsive twitchings nor momentary tremors such as are often found in progressive paralysis. The sensibility to heat, cold and cutaneous irritation were unimpaired, though the superficial temperature was slightly lowered, especially in the arms and hands. On electrical examination the irritability of the affected muscles was lessened generally, but the increased action of the muscles on both cathodal and anodal opening and closing were more marked when the electrode was placed directly over the motor point. The pupils responded to light and accommodation. The patient was not especially intelligent, his mental actions being sluggish though his judgment was firm and his emotions under control. After six months' treatment on the plans hereinbefore mentioned the patient has gained twenty-six pounds in weight; the superficial temperature of the affected muscles is normal; there is increased strength in the muscles and so far as can be discovered no atrophy in the previously unaffected parts.

A few weeks ago a younger brother, a boy of 11 years, was brought to me and upon examination was found to be afficted in the same way, but in a lesser degree, the commencement unknown. There is true atrophy and a minimum amount of adipose tissue along with stunted growth for the child's age.

May 1, 1896, the patient has not grown especially weaker and the good fibers are increased somewhat in strength. The electric reactions and other physical signs remain about the same. His general nutrition has increased somewhat during the past year and there has been no further noticeable involvement of muscles.

\section{GASTROSTOMY BY A CIRCULAR VALVE METHOD.}

BY EMANUEL J. SENN, M.D.

INSTRUCTOK IN SURGERY, RUSH MEDICAL COLLEGE, CHICAGO.

Gastrostony, since it was first suggested by Egeberg in 1837 and performed by Sedillot in 1849, has undergone many transformations in the evolution of technique. The primitive operations as done by Sedillot, Fenger, Foster, Durham, Langenbeck, Krönlein and Verneuil, consisted simply in making the external incision through the abdominal wall and fastening the stomach in the wound with sutures or steel needles as a support, and then incising it. There naturally was no resistance to the stomach contents, the great obstacle to gastrostomy. The operation fell into ill repute and practically lay dormant until the present decade, when it was revived and received an impetus in the modern methods of Von Hacker, Hahn, Witzel. Ssabanajew and Frank, in the hope of rectifying the 